\title{
An Unprecedented Use for Glycerol: Chemoselective Reducing Agent for Sulfoxides $\dagger$
}

\author{
Nuría García, Patricia García-García, Manuel A. Fernández-Rodríguez, Daniel García, María R. \\ Pedrosa, Francisco J. Arnáiz and Roberto Sanz*
}

\section{s Received (in $X X X, X X X)$ Xth $X X X X X X X X X 20 X X$, Accepted $X$ th $X X X X X X X X X 20 X X$} DOI: 10.1039/b000000x

\begin{abstract}
A new application for glycerol that expands its possibilities apart from green solvent and precursor of value-added products has been demonstrated. Simple, easily available, and environmentally friendly dioxomolybdenum(VI) complexes are highly efficient catalysts for the chemoselective sulfoxide 10 deoxygenation with this biomass-derived chemical feedstock. Both refined glycerol and crude glycerin can be used expanding the potential application of this reaction. Subsequent transformation of glycerol during this reductive process has also been investigated.
\end{abstract}

\section{Introduction}

The increasing demand for biodiesel has caused in recent years 15 a continuous grow in the production of glycerol, generated as a by-product of this process, leading to an oversupply of this renewable chemical that could be considered as an important biorefinery feedstock. ${ }^{1}$ Therefore, the efficient transformation of glycerol into valuable chemicals has attracted much attention 20 from both academia and industry. ${ }^{2}$ Due to its multifunctional structure, glycerol opens the door to the preparation of a large number of chemicals through different pathways such as oxidation, ${ }^{3}$ reduction, ${ }^{4}$ dehydration, ${ }^{5}$ esterification, ${ }^{6}$ etherification, ${ }^{7}$ or reforming to syngas. ${ }^{8}$ In addition, glycerol has 25 also found use as a sustainable solvent for green chemistry, ${ }^{9}$ although some problems associated with its high viscosity and the presence of potentially reactive hydroxyl groups should be considered. However, the use of glycerol as a reagent for promoting organic transformations is considerably less 30 developed, standing out the synthesis of glycerol-based acetals that are valuable chemical intermediates, ${ }^{10}$ and the metalcatalyzed transfer hydrogenation reaction from glycerol to unsaturated compounds, ${ }^{11}$ which can be also considered as an environmentally friendly route to glycerol oxidation. So, the

35 development of new applications, as well as the expansion of existing ones, for glycerol as a low-cost raw material constitutes an important goal in modern chemistry.

On the other hand, taking into account the significant role played by sulfoxides in asymmetric synthesis, ${ }^{12}$ their reduction to 40 the corresponding sulfides is an important organic reaction as this functionality can be cleanly cleaved from the target molecule once its presence is no longer required. So, several methodologies have been described to achieve this transformation, ${ }^{13}$ which has also biological relevance for avoiding oxidative damage of ${ }_{45}$ cells. ${ }^{14}$ However, the development of new green protocols for the reduction of sulfoxides bearing additional functionalities remains an important challenge. ${ }^{15}$

In the last years we have been involved in the development of new synthetic methodologies including reactions catalyzed by so easily available and environmentally friendly dioxomolybdenum(VI) complexes $^{16}$ for the reduction of oxygenated compounds such as sulfoxides, ${ }^{17}$ nitroaromatics, ${ }^{18}$ and $\mathrm{N}$-oxides. ${ }^{19}$ Looking for new and cleaner reagents that could act as oxygen-acceptors in Mo-catalyzed processes, ${ }^{20}$ we have ${ }_{55}$ recently reported the use of pinacol (2,3-dimethyl-2,3-butanediol) as a reducing agent for the reduction of sulfoxides and nitroarenes. ${ }^{21}$ Herein, we report the successful application of glycerol as reagent for the dioxomolybenum(VI)-catalyzed chemoselective deoxygenation of sulfoxides.

\section{${ }_{60}$ Results and discussion}

\section{Establishment of reaction conditions}

Based on our previous experience for the deoxygenation of sulfoxides with phosphites ${ }^{17}$ and pinacol, ${ }^{21}$ we selected bis $(p$ tolyl)sulfoxide as a model substrate and $\mathrm{MoO}_{2} \mathrm{Cl}_{2}(\mathrm{dmf})_{2}$ as ${ }_{65}$ catalyst for testing the possibility of using glycerol as oxygenacceptor (Table 1). ${ }^{22}$

Gratifyingly, we observed complete conversion of the sulfoxide and high isolated yields of the corresponding sulfide in different solvents with $5 \mathrm{~mol} \%$ of the dioxomolybdenum complex 70 and only 4 equiv. of glycerol at $170{ }^{\circ} \mathrm{C}$ (entries $\left.1-4\right) .{ }^{23}$ Moreover, without the use of an additional solvent the reactions also proceeded (entry 5) and by slightly increasing the amount of glycerol to 10 equiv. an almost quantitative yield of the sulfide could be isolated after overnight heating (entry 6). No 75 improvement was observed by a further increase of the amount of glycerol (entry 7), whereas lowering the catalyst loading (entry 8) or the reaction temperature (entry 9) led to incomplete conversions after $17 \mathrm{~h}$. Carrying out the reaction at $200{ }^{\circ} \mathrm{C}$ allowed us to isolate again the sulfide in high yield after only two 
hours (entry 10). At this temperature the catalyst loading could be cut up by half $(2.5 \mathrm{~mol} \%)$ without affecting the reaction time or the isolated yield (entry 11). ${ }^{24}$ Additional studies were also conducted at $200{ }^{\circ} \mathrm{C}$ to fine-tune the catalyst loading and reaction 5 time. These studies revealed that 1 order of magnitude or more decrease in the catalyst loading to $0.1-0.25 \mathrm{~mol} \%$ resulted in complete conversion and high yield by just extending the reaction time to 24-36 h (entries 12-13). On the other hand, the reaction could be performed under microwave irradiation reducing the 10 required time for the reduction to $15 \mathrm{~min}$ at $200{ }^{\circ} \mathrm{C}$ (entry 14) or even $5 \mathrm{~min}$ at $230^{\circ} \mathrm{C}$ (entry 15). Under these conditions better results were obtained by using toluene $\mathrm{e}^{23}$ as solvent and only a slight excess of glycerol (entries 17-18). Once again, the amount of catalyst employed could be diminished by an order of 15 magnitude by just extending the reaction time (entry 18). In addition, other dioxomolybdenum(VI) complexes such as $\mathrm{MoO}_{2} \mathrm{Cl}_{2}(\mathrm{dmso})_{2}, \quad \mathrm{MoO}_{2} \mathrm{Cl}_{2}\left(\mathrm{OPPh}_{3}\right)_{2}, \quad \mathrm{MoO}_{2} \mathrm{Cl}_{2}($ bipy $), \quad$ or $\mathrm{MoO}_{2}(\mathrm{acac})_{2}$ also resulted to be active catalysts for this transformation both under thermal and microwave conditions.

${ }_{20}$ Furthermore, and as expected, reactions conducted in the absence of the metal catalyst under conventional or microwave heating afforded no appreciable deoxygenation of the sulfoxide, although about $30 \%$ of disproportion of the sulfoxide was observed after $24 \mathrm{~h}$ at $200{ }^{\circ} \mathrm{C}$ leading to equimolar amounts of $\operatorname{bis}(p-$ 25 tolyl)sulfone and bis( $p$-tolyl)sulfide.

Table 1 Optimization of the reaction conditions for the reduction of bis $(p$ tolyl)sulfoxide with glycerol

\begin{tabular}{lllllll}
\hline & & & & \\
\end{tabular}

a Based on the starting bis( $p$-tolyl)sulfoxide; in brackets conversion estimated by ${ }^{1} \mathrm{H}$ NMR (300 MHz) from the crude reaction mixture. Yield not determined. ${ }^{c}$ Conducted under microwave irradiation (maximum wattage $300 \mathrm{~W}$ ); see ESI† for details.

\section{Scope of the sulfoxides reduction}

Our studies on reaction conditions showed that different combinations of catalyst loading/temperature/reaction time are efficient to accomplish the desired transformation both under 35 conventional or microwave heating. Among them, we selected $5.0 \mathrm{~mol} \%[\mathrm{Mo}] / 170{ }^{\circ} \mathrm{C} /$ overnight (Method A), $2.5 \mathrm{~mol} \%[\mathrm{Mo}]$ / $200{ }^{\circ} \mathrm{C} / 2-4 \mathrm{~h}$ (Method B) and $2.5 \mathrm{~mol} \%$ [Mo] / MW $230{ }^{\circ} \mathrm{C} / 5$ $\min ($ Method C) to check the scope of the reduction process. Using these conditions, the deoxygenation of diverse 40 representative sulfoxides was examined (Table 2). Thus, different diaryl and alkyl aryl sulfoxides reacted under the selected optimized conditions to afford high yields of the corresponding sulfides. Notably, starting sulfoxides bearing additional reducible functionalities such as halogens, $\mathrm{C}-\mathrm{C}$ multiple bonds, cyano or 45 ester groups could be chemoselectively deoxygenated to the corresponding sulfides remaining unaffected the additional substituent (entries 14-26). Remarkably, in the case of methyl 4nitrophenyl sulfoxide no reduction of the nitro group was observed (entries 27-29). ${ }^{25}$

50 In addition, this method can be applied to the multigram synthesis of sulfides. For instance, high yields were obtained in the reduction of $5.76 \mathrm{~g}$ of bis(p-tolyl)sulfoxide under both conventional heating and microwave-assisted conditions (Scheme 1). Interestingly, the deoxygenation of $2.30 \mathrm{~g}$ of this sulfoxide ${ }_{55}$ could also be carried out lowering the catalyst loading to 0.25 mol\% without affecting the yield of the process (Scheme 1).

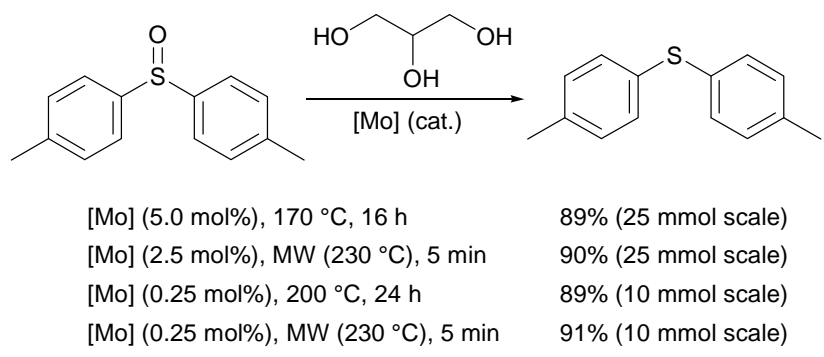

Scheme 1 Multi-gram reduction of bis(p-tolyl)sulfoxide.

60 The stability of a catalyst and its potential for reusability are important factors for evaluating the sustainability of the catalytic system and practical applications. We performed a recycling study for the dioxomolybdenum complex by using the deoxygenation of bis( $p$-tolyl)sulfoxide as a test reaction. After ${ }_{65}$ completion of the first reaction under conventional heating (200 ${ }^{\circ} \mathrm{C}, 4 \mathrm{~h}$ ) to yield the corresponding bis( $p$-tolyl)sulfide, the organic compound was easily extracted with hot toluene $\left(70-80^{\circ} \mathrm{C}\right)$ from the glycerolic phase containing the catalyst. After the addition of a new batch of sulfoxide the second and following runs were 70 performed again under the same reaction conditions with similar catalyst activity. ${ }^{26} \mathrm{We}$ were able to reuse the catalytic system for at least five times with a negligible change in its activity (Scheme 2). ${ }^{27}$ 


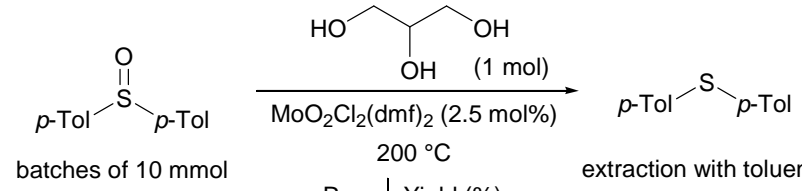

\begin{tabular}{c|c} 
Run & Yield (\%) \\
\hline 1 & 89 \\
2 & 88 \\
3 & 87 \\
4 & 90 \\
5 & 86
\end{tabular}

Scheme 2 Recycling study of the Mo-catalyzed reduction of bis( $p$ tolyl)sulfoxide with glycerol.

Table 2 Reduction of sulfoxides with glycerol catalyzed by $5 \mathrm{MoO}_{2} \mathrm{Cl}_{2}(\mathrm{dmf})_{2}$

$\mathrm{Method}^{a}\left(170\right.$ or $\left.200^{\circ} \mathrm{C}\right)$ or
$\mathrm{MW}\left(230^{\circ} \mathrm{C}\right)$

${ }^{a}$ Method A: $170{ }^{\circ} \mathrm{C}, 5.0 \mathrm{~mol} \%$ [Mo], overnight; Method B: $200{ }^{\circ} \mathrm{C}, 2.5$ mol\% [Mo], 2-4 h; Method C: $230{ }^{\circ} \mathrm{C}, \mathrm{MW}, 2.5 \mathrm{~mol} \%$ [Mo], 5 min. ${ }^{b}$ Yield of crude sulfide (purity $>95 \%$ by ${ }^{1} \mathrm{H}$ NMR).

\section{Reduction of sulfoxides employing crude glycerol}

As pointed out in the introduction, glycerol is a major byproduct in the transesterification process of biodiesel production. The crude glycerol formed in these processes, usually called 10 glycerin, is a complex mixture of variable purity that usually contains methanol, water, inorganic salts and other organic materials depending on the methodology employed for the biodiesel generation. The purification of the crude glycerol is nowadays an energy-consuming process and, as a consequence, 15 an economic and technological concern in the biodiesel industry. Therefore, the direct usage of low-quality glycerol from biodiesel production is a main goal for glycerol revalorization.

With this idea in mind, we surveyed the viability of our developed methodology using crude glycerol. ${ }^{28}$ Even though the ${ }_{20}$ purity of the crude glycerol employed was as low as $5-8 \%$, we were pleased to find that the reduction of a series of representative sulfoxides occurred to full conversion at $200{ }^{\circ} \mathrm{C}$ in the presence of $2.5 \mathrm{~mol} \%$ of $\mathrm{MoO}_{2} \mathrm{Cl}_{2}(\mathrm{dmf})_{2}$ (Scheme 3). These reactions took place in similar reaction times and slightly lower 25 yields in comparison with the use of refined glycerol. ${ }^{29}$

$$
\text { 作 }
$$<smiles>Clc1ccc(Sc2ccc(Cl)cc2)cc1</smiles><smiles>CSc1ccc(Br)cc1</smiles><smiles>CSc1ccc(C#N)cc1</smiles>

$79 \%$

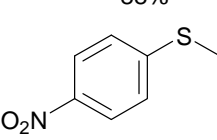

${ }^{\text {[a] }}$ All reactions were conducted with $1 \mathrm{mmol}$ of sulfoxide and $2.4 \mathrm{~g}$ of crude glycerol (ca. $5-8 \%$ purity)

Scheme 3 Reduction of sulfoxides with crude glycerol catalyzed by $\mathrm{MoO}_{2} \mathrm{Cl}_{2}(\mathrm{dmf})_{2}$.

\section{Transformation of glycerol in the reduction process}

After having established a new and useful application of glycerol as reagent and solvent for the molybdenum-catalyzed chemoselective reduction of sulfoxides, we turned our attention to the transformation of the glycerol in the process. In this sense, 35 glycerol is a highly functionalized molecule that could be oxidized in diverse extent to a wide range of compounds depending on the catalyst, the oxidant and the reaction conditions. ${ }^{3 e}$

To determine the extent of glycerol oxidation in the developed 40 reduction of sulfoxides, a series of experiments varying the ratio sulfoxide-glycerol were performed and are summarized in Scheme 4. These reactions were conducted using $\operatorname{bis}(p-$ tolyl)sulfoxide at $200{ }^{\circ} \mathrm{C}$ in the presence of $2.5 \mathrm{~mol} \%$ of molybdenum catalyst using mesitylene as solvent and the 45 conversion was estimated by ${ }^{1} \mathrm{H}$ NMR (300 MHz) after 9 hours. 
These data show that glycerol was able to completely reduce up to 6 equiv. of sulfoxide. Incomplete conversions (48-76\%), that correspond with the consumption of 6 equiv. or less, were reached in the assays with higher sulfoxide:glycerol molar ratios. 5 These results imply that, if one equivalent of glycerol is able to reduce 6 equiv. of sulfoxide, this equivalent of glycerol should be transformed in 2 equiv. of $\mathrm{CO}_{2}$ and one equivalent of formic acid to balance the redox reaction (Scheme 4).

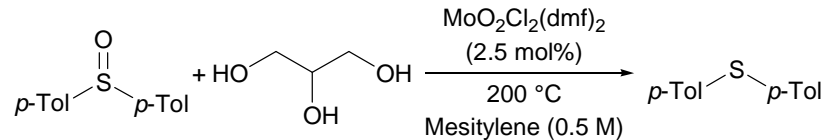

ratio sulfoxide:glycerol

1:1

3:1

$6: 1$

$7: 1$

$8: 1$

$12: 1$

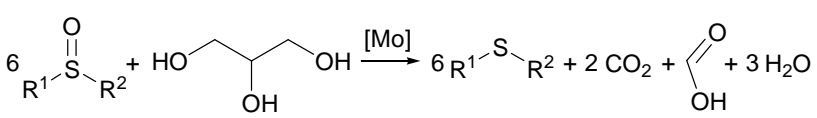

10 Scheme 4 Mo-catalyzed oxidation of glycerol with bis( $p$-tolyl)sulfoxide.

The glycerol oxidation is a complex process which could involve different pathways and furnish several oxidation products (Figure 1). The complete transformation of 6 equiv. of sulfoxide 15 in the presence of just 1 equiv. of glycerol indicates that the oxidation products formed from glycerol should be also oxidized by the sulfoxide under the reaction conditions to finally afford carbon dioxide and formic acid.

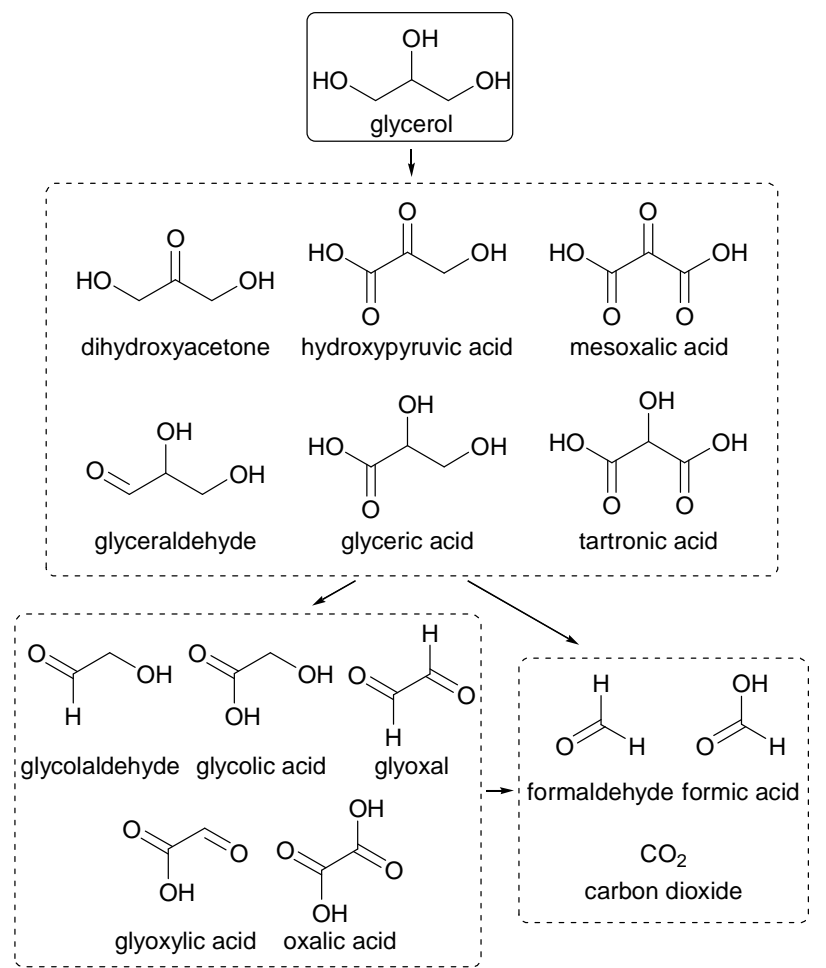

Fig. 1 Possible products generated by the oxidation of glycerol.
To prove the formation of formic acid and gain some insight into the glycerol transformation under the catalytic optimized conditions, different NMR assays were designed. First, we ${ }_{25}$ performed the reaction of DMSO- $d_{6}$ (6 equiv.) with glycerol (1 equiv.) at $170{ }^{\circ} \mathrm{C}$ and after $17 \mathrm{~h}$ we could observe in the ${ }^{13} \mathrm{C}$ NMR spectrum the formation of formic acid as main product as well as minor amounts of glycerol remaining. ${ }^{30}$ Reactions lowering the ratio DMSO- $d_{6}$ : glycerol were also conducted either 30 at $170{ }^{\circ} \mathrm{C}$ or at $200{ }^{\circ} \mathrm{C}$ and their ${ }^{13} \mathrm{C}$-NMR were measured. In all these spectra, even when using an equimolecular ratio of sulfoxide and glycerol, we essentially observed the signals of the formic acid and glycerol. ${ }^{30}$ These results suggest that, under the reaction conditions, the primary oxidation products generated 35 from glycerol are further oxidized by the sulfoxide and that these secondary oxidations are favoured over the glycerol oxidation.

To check these hypothesis we carried out the deoxygenation of bis(p-tolyl)sulfoxide using as reducing agent several of the compounds proposed in Figure 1. These reactions, summarized in 40 Table 3, were conducted under microwave heating, at either 180 or $230^{\circ} \mathrm{C}$, but varying the molar ratio sulfoxide:reductant in order to get information about the reduction capability of each species. Thus, equimolecular reactions of sulfoxide with dihidroxyacetone, tartronic acid, glycolaldehyde, glycolic acid 45 and glyoxylic acid occurred to full conversion and high yield either at 180 or $230^{\circ} \mathrm{C}$ (entries 4, 7, 8, 11, 12, 15, 16, 19, 20 and 23). These results confirm that these compounds, likely generated in the glycerol oxidation, are also able to reduce the sulfoxide to the corresponding sulfide in the presence of the molybdenum 50 catalyst and, additionally, that these compounds have a higher reducing power than glycerol, whose reaction at $180{ }^{\circ} \mathrm{C}$ gave only $50 \%$ conversion (entry 3 ). Notably, dihidroxyacetone, tartronic acid, glycolaldehyde, glycolic acid and glyoxylic acid could reduce the number of equivalents of sulfoxide required to be 55 completely converted into formic acid and $\mathrm{CO}_{2}$ (entries 5, 6, 9, $10,13,14,17,18,21$ and 22) thus suggesting the plausible intermediacy of these compounds during the deoxygenation process of sulfoxides by glycerol.

On the contrary, moderate to low conversions were achieved, ${ }_{60}$ even at extended reaction times, in analogous experiments conducted with glyoxal, oxalic acid, and formaldehyde as reductants (entries 24 and 26-30). These data reveal that, most probably, these compounds are not formed in the oxidation of glycerol or their derivatives under the reaction conditions.

65 Finally, we also checked that formic acid was not significantly oxidized by the sulfoxide under these conditions (entries 31 and 32 ), supporting the fact that this product will be the major one after the complete reduction of the sulfoxide. It is interesting to note that formic acid is of great interest as a chemical and 70 hydrogen carrier. ${ }^{31}$ 
Table 3 Oxidation products of glycerol as reductants of sulfoxides in the presence of $\mathrm{MoO}_{2} \mathrm{Cl}_{2}(\mathrm{dmf})_{2}$

\begin{tabular}{|c|c|c|c|c|c|}
\hline \multirow{2}{*}{$\begin{array}{l}p \text {-Tol } \\
\text { Entry } \\
\end{array}$} & $p$-Tol & $\begin{array}{l}\text { Reducing } \\
\text { agent } \\
\text { (n equiv.) }\end{array}$ & $\begin{array}{c}\mathrm{MoO}_{2} \mathrm{Cl}_{2}(\mathrm{dmf})_{2} \\
(2.5 \mathrm{~mol} \%) \\
\text { Toluene }(1 \mathrm{~mL}) \\
\mathrm{MW}, \mathrm{T}, \mathrm{t}\end{array}$ & $p$-Tol & $p$-Tol \\
\hline & Reducing agent & n equiv. & $\mathrm{T}\left({ }^{\circ} \mathrm{C}\right)$ & Time (min) & Yield $^{a}(\%)$ \\
\hline 1 & $\mathrm{OH}$ & 1 & 230 & 5 & $91(100)$ \\
\hline 2 & $\mathrm{HO}_{>}$ & 6 & 230 & 5 & $93(100)$ \\
\hline 3 & glycerol & 1 & 180 & 5 & $(50)^{b}$ \\
\hline 4 & & 1 & 230 & 5 & $92(100)$ \\
\hline 5 & & 4 & 230 & 10 & $94(100)$ \\
\hline 6 & & 5 & 230 & 20 & $(86)^{b}$ \\
\hline 7 & & 1 & 180 & 5 & $97(100)$ \\
\hline 8 & $\mathrm{OH}$ & 1 & 230 & 5 & $93(100)$ \\
\hline 9 & & 3 & 230 & 5 & $97(100)$ \\
\hline 10 & & 4 & 230 & 5 & $(74)^{b}$ \\
\hline 11 & tartronic acid & 1 & 180 & 5 & $94(100)$ \\
\hline $12^{c}$ & & 1 & 230 & 5 & $91(100)$ \\
\hline $13^{c}$ & $\mathrm{OH}$ & 3 & 230 & 5 & $92(100)$ \\
\hline $14^{c}$ & & 4 & 230 & 20 & $(67)^{b}$ \\
\hline $15^{c}$ & glycolald & 1 & 180 & 5 & $93(100)$ \\
\hline 16 & & 1 & 230 & 5 & $96(100)$ \\
\hline 17 & & 3 & 230 & 5 & $93(100)$ \\
\hline 18 & & 4 & 230 & 5 & $(73)^{b}$ \\
\hline 19 & glycolic acid & 1 & 180 & 5 & $92(100)$ \\
\hline 20 & & 1 & 230 & 5 & $87(100)$ \\
\hline 21 & & 2 & 230 & 10 & $92(100)$ \\
\hline 22 & alvo & 3 & 230 & 5 & $(65)^{b}$ \\
\hline 23 & glyoxylic acid & 1 & 180 & 5 & $93(100)$ \\
\hline $24^{e}$ & $\mathrm{H}$ & 1 & 230 & 10 & $(75)^{b}$ \\
\hline $25^{e}$ & & 3 & 230 & 10 & $(41)^{b}$ \\
\hline $26^{e}$ & glyoxal & 1 & 180 & 10 & $(50)^{b}$ \\
\hline 27 & & 1 & 230 & 10 & $(69)^{b}$ \\
\hline 28 & $\begin{array}{cc}\text { HO } & \text { O } \\
\text { oxalic acid }\end{array}$ & 1 & 180 & 10 & $(<5)$ \\
\hline $29^{e}$ & $\mathrm{O} \rightleftharpoons \mathrm{H}$ & 1 & 230 & 10 & (54) \\
\hline $30^{e}$ & $\stackrel{H}{\text { formaldehyde }}$ & 1 & 180 & 5 & $(<5)$ \\
\hline 31 & $\mathrm{O}=\mathrm{OH}$ & 1 & 230 & 5 & (26) \\
\hline 32 & formic acid & 1 & 180 & 5 & (18) \\
\hline
\end{tabular}

${ }^{a}$ Based on the starting bis(p-tolyl)sulfoxide; in brackets conversion estimated by ${ }^{1} \mathrm{H}$ NMR $(300 \mathrm{MHz})$ from the crude reaction mixture. ${ }^{b}$ Yield not determined. ${ }^{c}$ Commercially available glycolaldehyde dimmer was used. ${ }^{d}$ Reactions performed with aqueous glyoxal (40\%). ${ }^{e}$ Reactions performed with aqueous formaldehyde (37\%).

\section{Conclusions}

5 In summary, we have demonstrated that glycerol can be successfully employed as a solvent and reducing agent in the Mocatalyzed chemoselective deoxygenation of sulfoxides. Previously described deoxygenating agents for the reduction of sulfoxides, such as phosphorous(III) reagents or silanes, have 10 been replaced by this widely available feedstock. The process can be performed in air and the use of this inexpensive and green reaction medium allows easy product isolation and catalyst recycling. Notably, crude glycerin, containing as less as $5-8 \%$ of glycerol, can also be used as reducing agent. In addition, we have 15 shown that sulfoxides are able to convert glycerol into formic acid, which was identified by using ${ }^{1} \mathrm{H}$ and ${ }^{13} \mathrm{C}$ NMR spectroscopy. Overall, the results reported herein represent a new use for glycerol as solvent and reagent for synthetic organic chemistry, an emerging challenge leading to the revalorization of 20 a waste generated by the biodiesel industry.

\section{Experimental}

\section{General procedures for the reduction of sulfoxides with glycerol}

A mixture of glycerol (921 mg, 10 equiv.), sulfoxide ( $1 \mathrm{mmol})$ 25 and $\mathrm{MoO}_{2} \mathrm{Cl}_{2}(\mathrm{dmf})_{2}(17 \mathrm{mg}, 5 \mathrm{~mol} \%$ for Method A; $9 \mathrm{mg}, 2.5$ mol $\%$ for Method B) was heated at $170{ }^{\circ} \mathrm{C}$ overnight (Method A) or $200{ }^{\circ} \mathrm{C}$ for $2-4 \mathrm{~h}$ (Method B), until complete consumption of the starting material (determined by GC-MS analysis). Alternatively a mixture of glycerol $(111 \mathrm{mg}, 1.2 \mathrm{mmol})$, sulfoxide $30(1 \mathrm{mmol})$ and $\mathrm{MoO}_{2} \mathrm{Cl}_{2}(\mathrm{dmf})_{2}(9 \mathrm{mg}, 2.5 \mathrm{~mol} \%)$ in toluene $(1$ $\mathrm{mL}$ ) was irradiated in a sealed tube in the microwave cavity at $230{ }^{\circ} \mathrm{C}$ for $5 \mathrm{~min}$ (Method $\mathrm{C}$ ). Whatever the reaction procedure, the reaction mixture was cooled to room temperature and $\mathrm{Et}_{2} \mathrm{O}$ (20 mL) and $\mathrm{H}_{2} \mathrm{O}(20 \mathrm{~mL})$ were added. The layers were separated 35 and the aqueous layer extracted with $\mathrm{Et}_{2} \mathrm{O}(2 \times 20 \mathrm{~mL})$. The combined organic layers were dried over anhydrous $\mathrm{Na}_{2} \mathrm{SO}_{4}$, filtered, and the solvents were removed under reduced pressure. The corresponding sulfide was obtained in almost pure form without further purification in the yields reported in Table 2. 40

\section{Procedure for the catalyst recycling process}

A mixture of glycerol (92 g, 100 equiv.), bis(p-tolyl)sulfoxide (2.3 g, $10 \mathrm{mmol})$ and $\mathrm{MoO}_{2} \mathrm{Cl}_{2}(\mathrm{dmf})_{2}$ (90 mg, $2.5 \mathrm{~mol} \%$ ) was heated at $200{ }^{\circ} \mathrm{C}$ for $4-6 \mathrm{~h}$. The reaction mixture was cooled to

$45100{ }^{\circ} \mathrm{C}$ and extracted with hot toluene $(3 \times 50 \mathrm{~mL})$. The combined organic layers were dried over anhydrous $\mathrm{Na}_{2} \mathrm{SO}_{4}$, filtered, and the solvents were removed under reduced pressure. $\operatorname{Bis}(p-$ tolyl)sulfide was obtained in almost pure form without further purification in the yields reported in Scheme 2. The glycerolic ${ }_{50}$ phase was reused in the next cycle.

\section{General procedure for the reduction of sulfoxides with crude} glycerol

A mixture of crude glycerol (2.36 g, ca. 5-8\% purity, ca. 2 55 equiv.), sulfoxide $(1 \mathrm{mmol})$ and $\mathrm{MoO}_{2} \mathrm{Cl}_{2}(\mathrm{dmf})_{2}(9 \mathrm{mg}, 2.5$ mol\%) was heated at $200{ }^{\circ} \mathrm{C}$ for $2-7 \mathrm{~h}$ in an open flask until complete consumption of the starting material (determined by GC-MS analysis). The reaction mixture was cooled to room temperature and $\mathrm{Et}_{2} \mathrm{O}(20 \mathrm{~mL})$ and $\mathrm{H}_{2} \mathrm{O}(20 \mathrm{~mL})$ were added. The 60 layers were separated and the aqueous layer extracted with $\mathrm{Et}_{2} \mathrm{O}$ $(2 \times 20 \mathrm{~mL})$. The combined organic layers were dried over anhydrous $\mathrm{Na}_{2} \mathrm{SO}_{4}$, filtered, and the solvents were removed under reduced pressure. The corresponding sulfide was obtained in almost pure form without further purification in the yields ${ }_{65}$ reported in Scheme 3. 
General procedure for the reduction of sulfoxides using oxidation products from glycerol as reducing agents

A mixture of bis(p-tolyl)sulfoxide (230 $\mathrm{mg}, 1 \mathrm{mmol})$, the appropriate amount of reducing agent (1-6 equiv.), and ${ }_{5} \mathrm{MoO}_{2} \mathrm{Cl}_{2}(\mathrm{dmf})_{2}(9 \mathrm{mg}, 2.5 \mathrm{~mol} \%)$ in toluene $(1 \mathrm{~mL})$ was irradiated in a sealed tube in the microwave cavity at 180 or 230 ${ }^{\circ} \mathrm{C}$ for $5 \mathrm{~min}$. The reaction mixture was cooled to room temperature and $\mathrm{Et}_{2} \mathrm{O}(20 \mathrm{~mL})$ and $\mathrm{H}_{2} \mathrm{O}(20 \mathrm{~mL})$ were added. The layers were separated and the aqueous layer extracted with $\mathrm{Et}_{2} \mathrm{O}$ $10(2 \times 20 \mathrm{~mL})$. The combined organic layers were dried over anhydrous $\mathrm{Na}_{2} \mathrm{SO}_{4}$, filtered, and the solvents were removed under reduced pressure to give bis( $p$-tolyl)sulfide in the conversions and yields reported in Table 3 .

\section{Acknowledgements}

$15 \mathrm{We}$ are grateful to the Ministerio de Ciencia e Innovación (MICINN) and FEDER (CTQ2010-15358 and CTQ200909949/BQU) and Junta de Castilla y León (BU021A09 and GR172) for financial support. P.G-G. and M.A.F.-R. thank MICINN for "Juan de la Cierva" and "Ramón y Cajal" contracts.

\section{${ }_{20}$ Notes and references}

Departamento de Química, Facultad de Ciencias, Universidad de Burgos, Pza. Misael Bañuelos s/n, 09001-Burgos, Spain. Fax: (+34) 947258831; E-mail: rsd@ubu.es

$\dagger$ Electronic Supplementary Information (ESI) available: NMR spectra of 25 the products and experimental details for the recycling study. See DOI: $10.1039 / \mathrm{b} 000000 \mathrm{x} /$

1 J. J. Bozell and G. R. Petersen, Green Chem., 2010, 12, 539-554.

2 (a) M. Pagliaro, R. Ciriminna, H. Kimura, M. Rossi and C. Della Pina, Angew. Chem., Int. Ed., 2007, 46, 4434-4440; (b) A. Behr, J. Eilting, K. Irawadi, J. Leschinski and F. Lindner, Green Chem., 2008, 10, 13-30; (c) C.-H. Zhou, J. N. Beltramini, Y.-X. Fan and G. Q. Lu, Chem. Soc. Rev., 2008, 37, 527-549; (d) F. Jérôme, Y. Pouilloux and J. Barrault, ChemSusChem, 2008, 1, 586-613.

3 (a) Y. Kwon, K. J. P. Schouten and M. T. M. Koper, ChemCatChem, 2011, 3, 1176-1185; (b) C.-H. Zhou, J. N. Beltramini, C.-X. Lin, Z.P. Xu, G. Q. Lu and A. Tanksale, Catal. Sci. Technol., 2011, 1, 111-122; (c) G. L. Brett, Q. He, C. Hammond, P. J. Miedziak, N. Dimitratos, M. Sankar, A. A. Herzing, M. Conte, J. A. LópezSánchez, C. J. Kiely, D. W. Knight, S. H. Taylor and G. J. Hutchings, Angew. Chem. Int. Ed., 2011, 50, 10136-10139; (d) E. Skrzyńska, J. Ftouni, J.-S. Girardon, M. Capron, L. Jalowiecki-Duhamel, J.-F. Paul and F. Dumeignil, ChemSusChem, 2012, 5, 2065-2078; (e) For a review, see: B. Katryniok, H. Kimura, E. Skrzyńska, J.-S. Girardon, P. Fongarland, M. Capron, R. Ducoulombier, N. Mimura, S. Paul and F. Dumeignil, Green Chem., 2011, 13, 1960-1979.

4 (a) Hydrogenolysis: J. Chaminand, L. A. Djakovitch, P. Gallezot, P. Marion, C. Pinel and C. Rosier, Green Chem., 2004, 6, 359-361; (b) S. Zhu, Y. Zhu, S. Hao, H. Zheng, T. Mo and Y. Li, Green Chem., 2012, 14, 2607-2616; (c) N. D. Kim, J. R. Park, D. S. Park, B. K. Kwak and J. Yi, Green Chem., 2012, 14, 2638-2646; (d) For dehydroxylation reactions, see: J. ten Dam and U. Hanefeld, ChemSusChem, 2011, 4, 1017-1034.

5 (a) B. Katryniok, S. Paul, V. Bellière-Baca, P. Rey and F. Dumeignil, Green Chem., 2010, 12, 2079-2098; (b) For oxidehydration reactions, see: M. D. Soriano, P. Concepción, J. M. López Nieto, F. Cavani, S. Guidetti and C. Trevisanut, Green Chem., 2011, 13, 2954-2962.

6 (a) X. Liu, H. Ma, Y. Wu, C. Wang, M. Yang, P. Yan and U. WelzBiermann, Green Chem., 2011, 13, 697-701; (b) For the preparation

60 of glycerol carbonate from glycerol, see: J. Hu, Y. Gu, Z. Guan, J. Li, W. Mo, T. Li and G. Li, ChemSusChem, 2011, 4, 1767-1772; (c) Ch.
Ramesh Kumar, K. Jagadeeswaraiah, P. S. Sai Prasad and N. Lingaiah, ChemCatChem, 2012, 4, 1360-1367.

7 (a) A. M. Ruppert, J. D. Meeldijk, B. W. M. Kuipers, B. H. Erné and B. M. Weckuysen, Chem. Eur. J., 2008, 14, 2016-2024; (b) Y. Gu, A. Azzouzi, Y. Pouilloux, F. Jérôme and J. Barrault, Green Chem., 2008, 10, 164-167; (c) Y. Shi, W. Dayoub, G.-R. Chen and M. Lemaire, Green Chem., 2010, 12, 2189-2195; (d) P. Gaudin, R. Jacquot, P. Marion, Y. Pouilloux and F. Jérôme, Catal. Sci. Technol., 2011, 1, 616-620; (e) P. Goudin, R. Jacquot, P. Marion, Y. Pouilloux and F. Jérôme, ChemSusChem, 2011, 4, 719-722.

8 R. R. Soares, D. A. Simonetti and J. A. Dumesic, Angew. Chem., Int. Ed., 2006, 45, 3982-3985.

9 (a) Y. Gu and F. Jérôme, Green Chem., 2010, 12, 1127-1138; (b) A. E. Díaz-Álvarez, J. Francos, B. Lastra-Barreira, P. Crochet and V. Cadierno, Chem. Commun., 2011, 47, 6208-6227.

10 (a) C. Crotti, E. Farnetti and N. Guidolin, Green Chem., 2010, 12, 2225-2231; (b) L. Li, T. K. Korányi, B. F. Sels and P. P. Pescarmona, Green Chem., 2012, 14, 1611-1619.

8011 (a) E. Farnetti, J. Kaspar and C. Crotti, Green Chem., 2009, 11, 704-709; (b) A. E. Díaz-Álvarez, P. Crochet and V. Cadierno, Catal. Commun., 2011, 13, 91-96; (c) A. Azua, J. A. Mata and E. Peris, Organometallics, 2011, 30, 5532-5536; (d) A. Dibenedetto, P. Stufano, F. Nocito and M. Aresta, ChemSusChem, 2011, 4, 13111315; (e) X. Cui, C. Zhang, F. Shi and Y. Deng, Chem. Commun., 2012, 48, 9391-9393.

12 M. C. Carreño, Chem. Rev., 1995, 95, 1717-1760.

13 M. Madesclaire, Tetrahedron, 1988, 44, 6537-6580.

14 J. H. Enemark and J. J. A. Cooney, Chem. Rev., 2004, 104, 1175-1200.

15 For recent examples, see: (a) A. C. Fernandes, J. A. Fernandes, C. C. Romão, L. F. Veiros and M. J. Calhorda, Organometallics, 2010, 29, 5517-5525; (b) S. Enthaler, Catal. Sci. Technol., 2011, 1, 104-110.

16 (a) R. Sanz and M. R. Pedrosa, Curr. Org. Synth., 2009, 6, 239-263; (b) R. Sanz and M. R. Pedrosa, Adv. Org. Synth., 2012, 4, 183-267.

17 R. Sanz, J. Escribano, R. Aguado, M. R. Pedrosa and F. J. Arnáiz, Synthesis, 2004, 1629-1632.

18 R. Sanz, J. Escribano, M. R. Pedrosa, R. Aguado and F. J. Arnáiz, Adv. Synth. Catal., 2007, 349, 713-718.

10019 R. Sanz, J. Escribano, Y. Fernández, R. Aguado, M. R. Pedrosa and F. J. Arnáiz, Synlett, 2005, 1389-1392.

20 Alternative reductants such as silanes, boranes, and hydrogen have also been used for the Mo-catalyzed deoxygenation of sulfoxides. See: (a) A. C. Fernandes and C. C. Romão, Tetrahedron, 2006, 62, 9650-9654; (b) A. C. Fernandes and C. C. Romão, Tetrahedron Lett., 2007, 48, 9176-9179; (c) P. M. Reis, P. J. Costa, C. C. Romão, J. A. Fernandes, M. J. Calhorda and B. Royo, Dalton Trans., 2008, 1727-1733.

21 N. García, P. García-García, M. A. Fernández-Rodríguez, R. Rubio, M. R. Pedrosa, F. J. Arnáiz and R. Sanz, Adv. Synth. Catal., 2012, 354, 321-327.

22 Glycerol USP (99.7\% min.) was purchased from Comercial Farmacéutica Castellana, S.A. and can be obtained from $1.25 \mathrm{~kg}$ $(2.02 € / \mathrm{kg})$ till $1250 \mathrm{~kg}$ containers $(0.93 € / \mathrm{kg})$.

11523 Glycerol is not miscible with these solvents although at the temperature reaction the mixtures become more or less homogeneous.

24 Further decreasing of the reaction time till $1 \mathrm{~h}$ led to incomplete conversion $(54 \%)$

12025 Using pinacol as a reducing agent nitroaromatics were reduced to the corresponding aniline derivatives. See ref. 21.

26 Slightly longer reaction times (ca. $6 \mathrm{~h}$ ) were needed for second and following runs.

27 In the sixth run a ca. $75 \%$ of conversion was observed after $24 \mathrm{~h}$ under the reaction conditions.

28 We obtained crude glycerol from Bionor (Berantevilla, Araba, Spain) with a glycerol and water contents among 5-8\% and $60-80 \%$, respectively, whereas methanol content was less than $5 \%$.

29 The reactions were performed in an open vessel and so, most of the solvent (mainly water) was removed along the process. The crude product was extracted with diethyl ether from the dried residue.

30 See Electronic Supporting Information for details. 
31 For an interesting hydrogen transfer reaction from glycerol to $\mathrm{CO}_{2}$ affording formic and glycolic acids, see: A. Dibenedetto, P. Stufano,

F. Nocito and M. Aresta, ChemSusChem, 2011, 4, 1311-1315. 